\title{
Sugammadex administration shortens reversal times but not operating room turnover times
}

\author{
Garrett Enten ${ }^{1}$, Michael Albrink ${ }^{2}$, Jin Deng ${ }^{3}$, Giorgio Melloni ${ }^{4}$, Enrico M. Camporesi*1 ${ }^{*}$, Devanand Mangar ${ }^{5}$ \\ ${ }^{1}$ TeamHealth Anesthesia Research Institute, Tampa, FL, United States \\ ${ }^{2}$ University of South Florida, Department of Surgery, Tampa, FL, United States \\ ${ }^{3}$ University of South Florida Morsani College of Medicine, Tampa, FL, United States \\ ${ }^{4}$ Harvard University, T.H. Chan School of Public Health, Boston, MA, United States \\ ${ }^{5}$ TeamHealth Anesthesia, Tampa, FL, United States
}

Received: March 28, 2019

DOI: $10.5430 /$ css.v5n1p27

\author{
Accepted: July 8, 2019 \\ Online Published: July 17, 2019 \\ URL: https://doi.org/10.5430/css.v5n1p27
}

\begin{abstract}
Objective: Current literature debates whether administration of sugammadex translates into a higher operating room (OR) efficiency when compared to neostigmine. This study is a blinded assessment of the effects of sugammadex versus neostigmine on OR efficiency as determined by time of reversal to time of the next case.

Methods: 50 patients undergoing abdominal surgery were randomized and evenly distributed into two groups, one receiving sugammadex $(4 \mathrm{mg} / \mathrm{kg})$ and the other, neostigmine $(0.06 \mathrm{mg} / \mathrm{kg})$ plus glycopyrrolate $(0.004 \mathrm{mg} / \mathrm{kg})$. Muscle paralysis was induced with intravenous rocuronium $(0.6 \mathrm{mg} / \mathrm{kg})$. Train of four (TOF) was monitored using acceleromyography every 10 minutes until reversal. Reversal agents were blindly prepared and administered during closing. TOF was then recorded every minute until a T4/T1 ratio $\geq 0.9$ was achieved. This was designated as time of complete reversal. Subsequently, post-reversal outcome measures were collected.

Results: Patients receiving sugammadex experienced a significantly shorter reversal time compared to those receiving neostigmine and glycopyrrolate $(2.92 \pm 1.71$ minutes vs. $7.68 \pm 5.63$ minutes; $p=.0002)$. No other outcome measures were significantly different between groups: time of OR ready for next case was 55.4 min vs. 56.1 min respectively; not significant.

Conclusions: While sugammadex was significantly faster at reversing patient neuromuscular blockade the time from reversal to patient extubation after Sugammadex was prolonged. This could be due to blinding, as blinded providers are unable to anticipate time of reversal and must compensate by making decisions at safe fixed intervals. This is reflected in that the time gained by administration of sugammadex is approximately equal to the delay experienced across all endpoints collected to the patients' actual discharge.
\end{abstract}

Key Words: Neuromuscular reversal agents, Sugammadex, Neostigmine, Operating room turnover time

\section{INTRODUCTION}

Patients undergoing open abdominal procedures such as hernia repair or colectomies require neuromuscular paralysis during surgical repair and fascia closure. Often, optimal clinical management requires profound neuromuscular blockade until abdominal closure. In contrast, rapid and complete reversal of neuromuscular paralysis at the end of these surgical procedures is an equally important step in ensuring optimal outcomes. Complete reversal of muscle paralysis is needed for reconstituting spontaneous muscle tone as well

*Correspondence: Enrico M. Camporesi; Email: enrico_camporesi@teamhealth.com; Address: TEAMHealth Research Institute, 1 Tampa General Circle Suite A327, Tampa, FL 33606, United States. 
as re-establishing effective spontaneous ventilation, gastrointestinal motility, swallowing, and natural muscular defenses. Slow or partial reversal of muscle paralysis can delay postoperative turnover time and cause sub-optimal outcomes for the patient. ${ }^{[1]}$

The cholinesterase inhibitor neostigmine is the most commonly used neuromuscular blocking agent antagonist because of its availability and versatility. However, neostigmine is not without its drawbacks. Neostigmine has a slow onset (3-5 min) and peak-effect (10-15 min). It has been associated with alteration of gastrointestinal motility and increased gastric/tracheal secretions which contribute to an increased risk of postoperative nausea and vomiting (PONV). ${ }^{[2,3]}$ Neostigmine alone in doses larger than 2.5 $\mathrm{mg}$ has been shown to increase the incidence of PONV. ${ }^{[4]}$ Neostigmine also has other parasympathetic side-effects such as bradycardia. In order to attenuate the negative parasympathetic effects of neostigmine, atropine or glycopyrrolate are given concomitantly. This may exacerbate issues with PONV as these drug combinations may be emetogenic. [5]

Although nausea and the parasympathetic side-effects associated with administration of neostigmine are issues in their own right, a more pressing matter within recent literature is the effect of incomplete reversal of deep neuromuscular blockade. A growing body of evidence has shown that postoperative residual neuromuscular blockade, defined as a train-of-four ratio $(\mathrm{T} 4 / \mathrm{T} 1)<0.9$, places patients at higher perioperative risk for respiratory complications and may increase hospital costs. ${ }^{[6-10]}$ A large multi-site trial of 1,571 adult patients undergoing elective open or laparoscopic abdominal surgery lasting $\leq 4$ hours from 32 hospitals across China conducted by Yu et al., showed $57.8 \%$ of patients given rocuronium as a non-depolarizing neuromuscular blocking agent (NMBA) that were reversed with neostigmine suffered from some form of residual neuromuscular blockade on extubation. ${ }^{[11]}$

An alternative reversal agent, sugammadex, has recently become available in the United States. Sugammadex is devoid of parasympathetic side-effects, but it has still been reported to induce PONV. ${ }^{[12,13]}$ A systematic review of 1,444 patients who received at least one dose of an NMBA intraoperatively during 2011 evaluated the efficacy of sugammadex compared to neostigmine found sugammadex to reduce all signs of residual postoperative paralysis. ${ }^{[14]}$ Patients who received neostigmine on average were more likely to have worse pulmonary outcomes across all ages and American Society of Anesthesiologists (ASA) physical status. ${ }^{[6]}$ Due to its different mechanism of action, sugammadex also has a faster onset ( $\leq 60-90 \mathrm{~s}$ ) and peak-effect (3-7 $\mathrm{min}) .{ }^{[15]}$ These factors all contribute to quicker reversal times and potentially better 28 post-operative outcomes when compared to neostigmine. ${ }^{[16]}$

Sugammadex may be faster and solve issues surrounding residual neuromuscular blockade, however whether this translates into a faster turn-over rate within the operating room (OR) has been a subject of debate within the literature. ${ }^{[17,18]}$ A majority of currently available literature has looked at the effects of sugammadex on time to discharge from the OR in an unblinded setting. It is our opinion that examining time from administration of reversal to discharge especially in an unblinded setting is somewhat equivocal as a measurement of OR efficiency. This study investigates the effects of sugammadex on OR turnover rate in a blinded setting.

\section{MATERIAls AND METHODS}

\subsection{Ethics}

The study conducted has been performed according to the Declaration of Helsinki and its procedures have been approved by the Western Institutional Review Board (WIRB) on June 9, 2016 (Protocol \#592107-43441875).

\subsection{Consent and randomization}

After obtaining approval from the local university IRB, a randomization list was generated in-hospital by the research pharmacy. Utilizing a two block stratified design, a total of 50 randomization slots were generated using gender and age as stratification factors to minimize imbalances between groups. Patients were set to be evenly distributed into two groups of 25 , one receiving sugammadex ( $4 \mathrm{mg} / \mathrm{kg})$ and the other, neostigmine $(0.06 \mathrm{mg} / \mathrm{kg})$ plus glycopyrrolate $(0.004$ $\mathrm{mg} / \mathrm{kg}$ ). The study population was culled from a selection of patients who were $\geq 18$ years of age and scheduled for ASA class I-III open ventral hernia repair or open colectomy. Subjects with bilateral ulnar nerve damage or known to have neuromuscular disorders impairing neuromuscular blockade such as myasthenia gravis were excluded from the study. For subject safety, those with significant renal dysfunction (determined as a creatinine clearance of $<30 \mathrm{~mL}$. $\min ^{-1}$ ); significant hepatic dysfunction; and/or hypersensitivity/allergy to sugammadex, opiates/opioids, rocuronium, or other medications used during general anesthesia were unable to participate in the study. After reviewing eligibility criteria and obtaining written consent from the patient, subjects were assigned to the next available treatment on the randomization schedule. A total of 72 patients were enrolled, 4 of which were excluded due to study ineligibility and 18 of which voluntarily withdrew consent or canceled/rescheduled their surgery. Of the remaining 50 patients, 10 were excluded from analysis ( 5 from each group) as they were the last case of the day and the OR turnover rate could not be calculated (see Figure 1). 


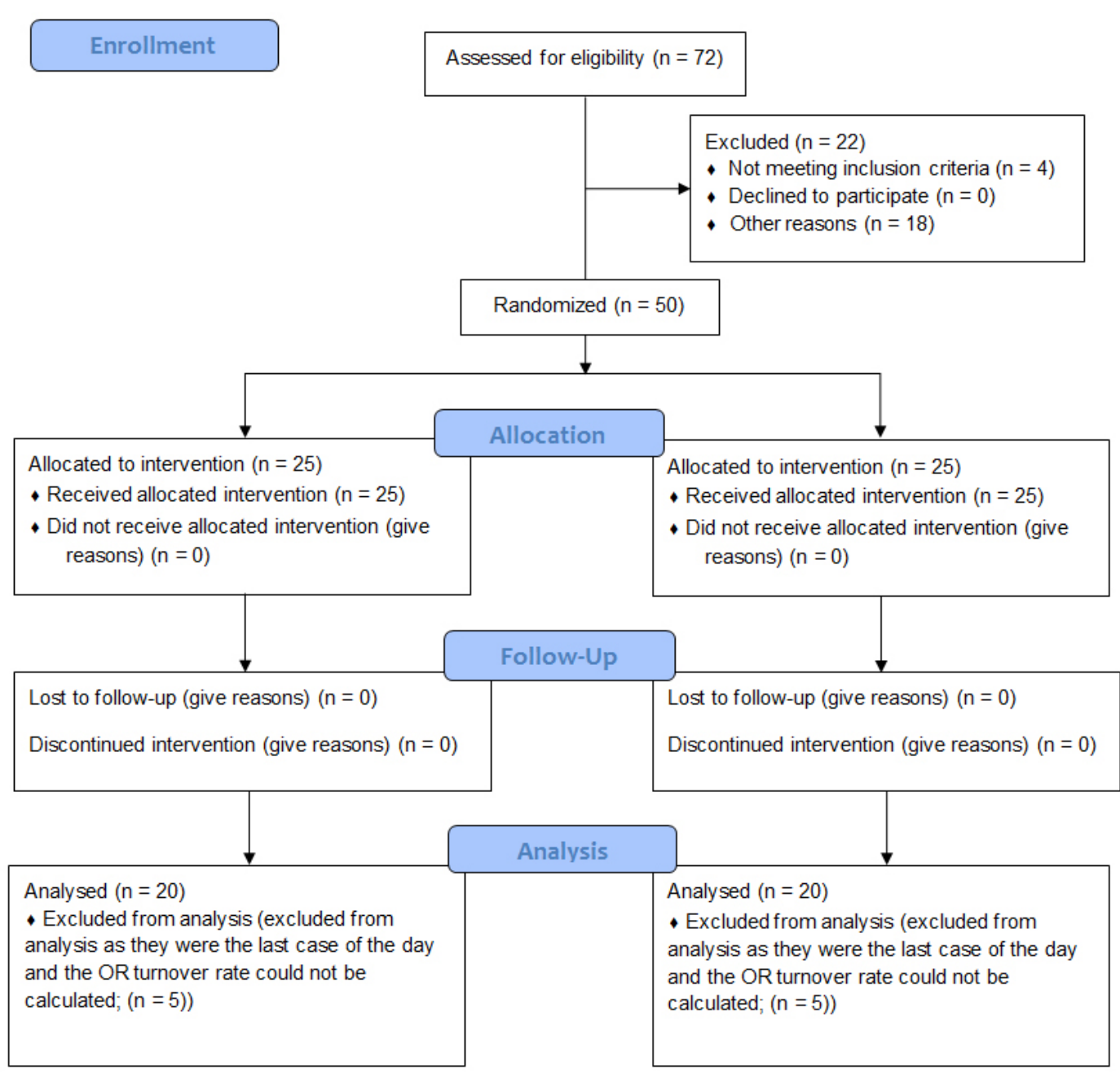

Figure 1. Of 72 total enrolled patients, four patients were ineligible to participate and eighteen patients withdrew or canceled their surgery. The remaining 50 patients were randomized into two even groups

\subsection{Operative course}

Patients were laid in a supine position with their arm without peripheral IV extended, supinated and fixed to an armboard. The thumb was left such that it was able to move freely without preload. Neuromuscular function was monitored by acceleromyography at the adductor pollicis muscle via supramaximal electrical stimulation of the ulnar nerve using the Stimpod NMS450 (X.Avant Technology; Pretoria, South Africa). The Stimpod was calibrated and stabilized as recommended by the manufacturer. Anesthesia was induced with propofol, intravenous opioids, and sevoflurane gas. Subsequently, a base line Train of Four (TOF) was obtained: this consists of four supramaximal stimulation twitches at the rate of 2 Hertz. The resulting four twitches are quantified by the Stimpod. The amplitude of the fourth twitch (T4) is divided by the amplitude of the first twitch (T1) to display the T4/T1 ratio. When $\mathrm{T} 4 / \mathrm{T} 1 \geq 90 \%$, the neuromuscular transmission is normal. When only the first and second twitch of a TOF remain, the muscle displays a moderate paralysis (TOF of 2/4). Muscle paralysis was then induced with intravenous rocuronium $(0.6 \mathrm{mg} / \mathrm{kg})$. After administration of the NMBA, patient TOF was taken with the Stimpod once per minute until a TOF of $2 / 4$ was reached at which point the patient was promptly intubated. After intubation, patient TOF was taken every $10 \mathrm{~min}$. A TOF of $2 / 4$ or less was maintained for the duration of the procedure until reversal. When needed, additional rocuronium $(0.15 \mathrm{mg} / \mathrm{kg})$ was given to maintain patient neuromuscular blockade. TOF at time of reversal was recorded to ensure groups were comparable.

\subsection{Reversal}

Patients, care providers, and clinical research staff were blinded to the reversal agent prior to completion of data analysis. Reversal agents were prepared according to the randomization schedule and patient weight by the in-hospital research pharmacy. Prepared syringes were marked as "sugammadex $(4 \mathrm{mg} / \mathrm{kg})$ or neostigmine $(0.06 \mathrm{mg} / \mathrm{kg})$ plus glycopyrrolate $(0.004 \mathrm{mg} / \mathrm{kg})$ " and entered into patient records as such. Reversal agents were pushed over 1 minute intravenously during surgical closing at which time TOF was recorded every minute until a T4/T1 ratio $\geq 0.9$ was achieved. Post-reversal outcome measures included times from T4/T1 
ratio $\geq 0.9$ to final dressing applied, patient extubation, OR discharge readiness (as determined by the attending anesthesiologist), OR actual discharge, post-anesthesia care unit (PACU) admit, PACU discharge, and OR turnover rate as determined by time from reversal to completion of first count for the next case. Secondary endpoints included post-operative pain scores, post-operative nausea/vomiting (PONV), average pain during floor stay, and length of floor stay.

\section{RESUlts}

Statistical tests were performed for each endpoint using unpaired two-tailed $t$-tests or chi-square analysis (see Table 1); significance was determined at a $p$-value $<.05$. No significant demographic differences were detected between the two groups in terms of age, race, ethnicity, gender ratio, or BMI. While no improvements in secondary outcomes were noted (i.e. PONV, VAS pain scores, or duration of hospitalization) it was noted that three patients $(12 \%)$ within the neostigmine plus glycopyrrolate group had residual neuro- muscular blockade $(\mathrm{T} 4 / \mathrm{T} 1$ ratio $<0.9)$ upon discharge from the OR. As described in previously literature, patients receiving sugammadex experienced a significantly shorter time from reversal to $\mathrm{T} 4 / \mathrm{T} 1$ ratio $\geq 0.9$ when compared to those receiving neostigmine and glycopyrrolate $(2.92 \pm 1.71 \mathrm{~min}-$ utes vs $7.68 \pm 5.63$ minutes; $p=.0002$ ). While sugammadex was significantly faster at reversing patient neuromuscular blockade, sugammadex patients experienced an increased time from $\mathrm{T} 4 / \mathrm{T} 1 \geq 0.9$ to extubation (neostigmine $7.74 \pm$ $6.89 \mathrm{~min}$ vs sugammadex $12.33 \pm 9.32 \mathrm{~min} ; p=.08$ ) and had no apparent effect on OR turnover rate (neostigmine $56.13 \pm 16.50$ min vs. sugammadex $55.40 \pm 16.38 \mathrm{~min} ; p=$ $.8891)$. This observation may be a direct result of blinding care providers. Blinded providers may be unable to anticipate time of reversal and compensate by making decisions at safe fixed intervals. This is reflected in that the time gained by administration of sugammadex is approximately equal to the delay experienced across all endpoints collected to the patients' actual discharge (see Figure 2).

Table 1. Post-reversal outcomes of neostigmine vs. sugammadex

\begin{tabular}{|c|c|c|c|c|}
\hline & $\begin{array}{l}\text { Neostigmine/Glycopyrrolate } \\
(\mathbf{n}=\mathbf{2 0})\end{array}$ & $\begin{array}{l}\text { Sugammadex } \\
(\mathbf{n}=\mathbf{2 0})\end{array}$ & Test & $p$-value \\
\hline Gender (\% Male) & $56 \%$ & $52 \%$ & Chi-Square & .7766 \\
\hline Race (\% White [\% Black]) & $72 \%(12 \%)$ & $88 \%(4 \%)$ & Chi-Square & .3558 \\
\hline \multirow[t]{2}{*}{ Ethnicity (\% Non-Hispanic) } & $84 \%$ & $76 \%$ & Chi-Square & .4795 \\
\hline & Mean $( \pm S D)$ & Mean $( \pm S D)$ & & \\
\hline Procedure Duration (min) & $71 \pm 40.53$ & $72 \pm 26.10$ & $t$-test & .9736 \\
\hline Total Rocuronium (mg) & $54 \pm 16.03$ & $57 \pm 16.76$ & $t$-test & .6072 \\
\hline Number of Twitches at Time of Reversal (__ of 4) & $2.08 \pm 1.22$ & $1.8 \pm 1.08$ & $t$-test & .3949 \\
\hline Time from Reversal to $\mathrm{T} 4 / \mathrm{T} 1 \geq 0.9(\mathrm{~min})$ & $7.68 \pm 5.63$ & $2.92 \pm 1.71$ & $t$-test & .0002 \\
\hline Time from $\mathrm{T} 4 / \mathrm{T} 1 \geq 0.9$ to When Dressing is Applied ( $\mathrm{min}$ ) & $6.4 \pm 5.91$ & $6.28 \pm 5.93$ & $t$-test & .9586 \\
\hline Time from $\mathrm{T} 4 / \mathrm{T} 1 \geq 0.9$ to Extubation $(\mathrm{min})$ & $7.74 \pm 6.89$ & $12.33 \pm 9.32$ & $t$-test & .0800 \\
\hline Time from $\mathrm{T} 4 / \mathrm{T} 1 \geq 0.9$ to Patient head lift/opening eyes $(\mathrm{min})$ & $8.55 \pm 9.14$ & $13.44 \pm 9.22$ & $t$-test & .0830 \\
\hline Time from $\mathrm{T} 4 / \mathrm{T} 1 \geq 0.9$ to or Discharge Ready (min) & $11.59 \pm 7.94$ & $15.12 \pm 8.40$ & $t$-test & .1474 \\
\hline Time from $\mathrm{T} 4 / \mathrm{T} 1 \geq 0.9$ to Actual or Discharge $(\mathrm{min})$ & $13.05 \pm 7.27$ & $17.76 \pm 8.90$ & $t$-test & .0549 \\
\hline Time from reversal to time or is ready for the next case ( $\mathrm{min})$ & $56.13 \pm 16.50$ & $55.40 \pm 16.38$ & $t$-test & .8891 \\
\hline Time from $\mathrm{T} 4 / \mathrm{T} 1 \geq 0.9$ to PACU Admit (min) & $14.77 \pm 7.16$ & $17.65 \pm 8.95$ & $t$-test & .2414 \\
\hline Time from $\mathrm{T} 4 / \mathrm{T} 1 \geq 0.9$ to Discharge Ready from PACU (min) & $103.26 \pm 41.02$ & $112.36 \pm 43.28$ & $t$-test & .3551 \\
\hline Average VAS Pain Score (PACU) & $5.69 \pm 1.81$ & $5.01 \pm 2.00$ & $t$-test & .3122 \\
\hline Average PONV Nuasea Score (PACU) & $1.48 \pm 2.09$ & $1.07 \pm 2.35$ & $t$-test & .5776 \\
\hline LOS (min) & $963.4 \pm 1,468.87$ & $2,408 \pm 3,974.04$ & $t$-test & .0946 \\
\hline Average VAS Pain (Floor Stay) & $2.69 \pm 2.25$ & $3.52 \pm 2.11$ & $t$-test & .1843 \\
\hline
\end{tabular}




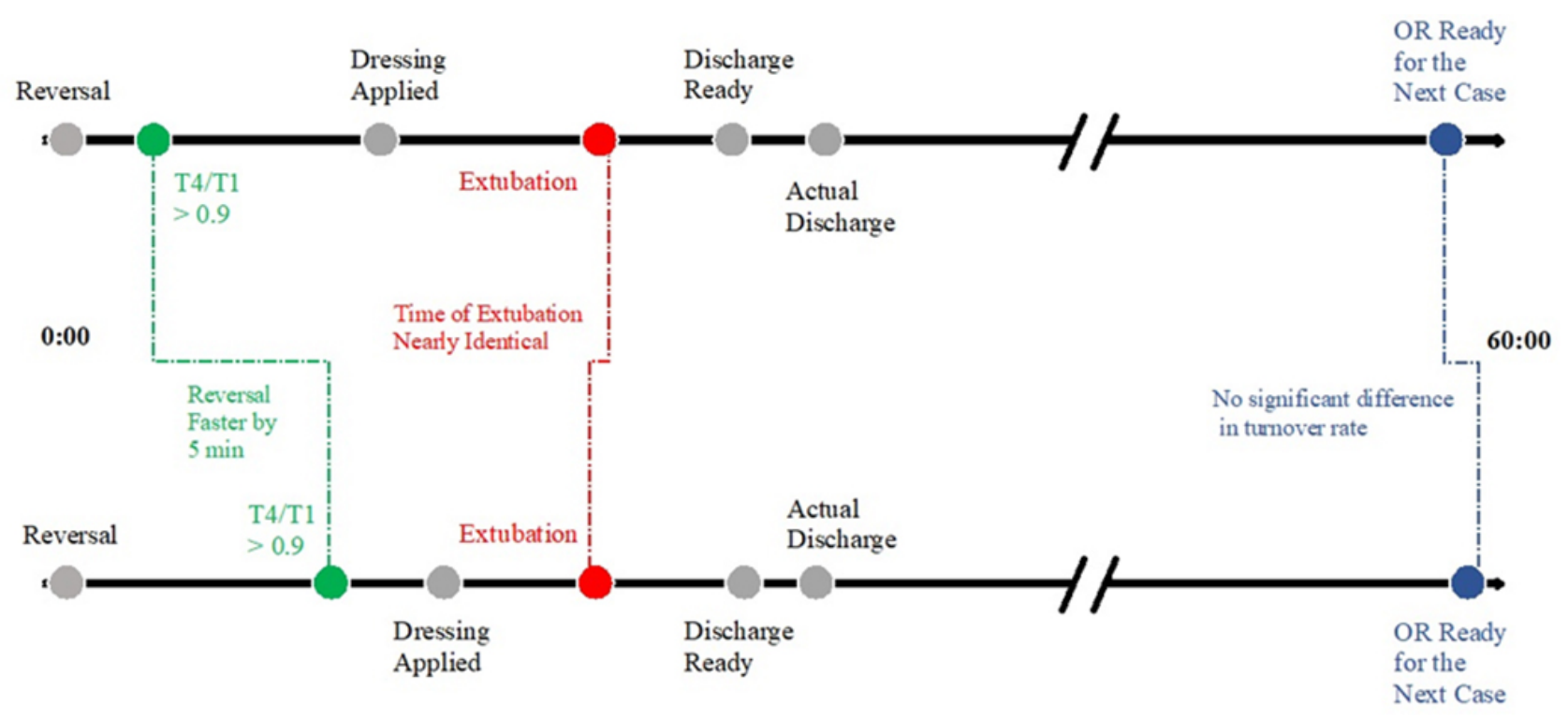

Figure 2. A time line comparison of average reversal with sugammadex vs. neostigmine and glycopyrrolate for 20 patients in each group (denotes approximately 45 minutes of elapsed time)

\section{Discussion}

As a cholinesterase inhibitor, neostigmine acts as a competitive inhibitor of acetylcholinesterase in order to increase the dissociation constant of acetylcholine in the synaptic cleft. This turns acetylcholine into a competitive antagonist of neuromuscular blocking agents at the postsynaptic nicotinic receptor. Sugammadex, however, functions distinctly from anticholinesterase neuromuscular antagonists, such as neostigmine, in that it selectively encapsulates steroidal neuromuscular blocking agents and allows for their rapid clearance from the tissues into surrounding blood plasma for renal elimination. ${ }^{[15]}$ This mechanism is ultimately both faster and more specific than neostigmine. ${ }^{[19-21]}$ This potentially can yield cost savings in the operative setting.

Operating room time is limited and highly resource intensive. As such, minimizing time spent within the OR plays a pivotal role in reducing costs and maximizing resource utilization. ${ }^{[22,23]}$ It is currently estimated that running a single simple OR at a tertiary care facility costs an average of 36-37 USD per minute and can range anywhere from 22-133 USD per minute. ${ }^{[24,25]}$ Reducing patient time to discharge, even if it is only by a few minutes, may result in decreased cost for the OR. A small study performed at a single center at the University of Padova estimates the use of sugammadex as first-choice reversal drug results in cost reduction of $£ 2.9(\approx$ 3.5 USD) per case. ${ }^{[26]}$ However this study failed to take into account the time gained from sugammadex administration, opting to only evaluate the use of sugammadex based on the cost of neuromuscular blockade management post drug administration. Further, the study is limited by its small scope and specific patient population who were judged to have an increased risk of complications with reversal of neuromuscular blockade by neostigmine.

A systematic economic review performed by Paton et al., states that two things need to be established to determine the cost effectiveness of sugammadex. ${ }^{[27]}$ Firstly, administration of sugammadex must result in a reduction in patient recovery times and can be consistently achieved in a clinical setting among a wide scope of patients with varying degrees of neuromuscular blockade when compared with neostigmine. Secondly, the time saved from administration of sugammadex must be reinvested into other productive means. A meta-analysis performed by Carron et al. demonstrates that sugammadex is associated with a significantly faster discharge from the OR to the PACU (mean difference $[\mathrm{MD}]=22.14 \mathrm{~min}, 95 \%$ CI $[14.62,29.67], p<.0001){ }^{[17]}$ However, the studies analyzed to reach this conclusion were in an un-blinded setting, which allowed providers to predict time of recovery from general anesthesia. In a blinded setting the time gained from the speed of sugammadex reversal is lost as providers cannot anticipate the speed of reversal and act accordingly (see Figure 2). This ultimately results in an identical turnover rate within the OR. Providing hospital staff with new target reversal times and accounting for the 4-5 minutes gained from the use of sugammadex as a reversal agent may increase OR efficiency as projected in prior studies.

In its current form, this study is limited by its small scope and sample size. Future considerations include increasing the number of study subjects and broadening the inclusion 
criteria to include other surgeries that require deep neuromuscular blockade to allow for sub-group analysis. This being said, determining the effects of blinding on randomized administration of neuromuscular blockade reversal agents on OR efficiency has few practical clinical implications. Nevertheless, this study may point to a potential confounding factor that should be considered during future experimental design regarding OR efficiency and neuromuscular blockade reversal.

\section{SUMMARY}

This study is a double blinded assessment of the effects of sugammadex versus neostigmine on OR efficiency as determined by time of reversal to time of the next case.

\section{A PPROVAL}

This study was approved by the Western IRB on June 9, 2016.

\section{FUNDING}

This study was sponsored in part by an Investigator Initiated grant with funds from Merck \& Co. Pharmaceutical Company, and by the TEAMHealth Research Institute (THRI).

\section{Clinical trials Registry NCT02860507.}

\section{Presentations}

Results of this paper were presented at the 113th ASA Annual Meeting October 11-14, 2018 in San Francisco, CA.

\section{CONFLiCTS OF INTEREST Disclosure}

The authors declare they have no conflicts of interest.

\section{REFERENCES}

[1] Feldheiser A, Aziz O, Baldini G, et al. Enhanced Recovery After Surgery (ERAS) for gastrointestinal surgery, part 2: consensus statement for anaesthesia practice. Acta Anaesthesiol Scand. 2016; 60(3) 289-334. PMid: 26514824. https://doi.org/10.1111/aas.12 651

[2] Tramer MR, Fuchs-Buder T. Omitting antagonism of neuromuscular block: effect on postoperative nausea and vomiting and risk of residual paralysis: a systematic review. Br J Anaesth. 1999; 82: 379-86. PMid: 10434820. https://doi.org/10.1093/bja/82.3.379

[3] Proakis AG, Harris GB. Comparative penetration of glycopyrrolate and atropine across the blood-brain and placental barriers in anesthetized dogs. Anesthesiology. 1978; 48: 339-44. PMid: 646152. https://doi.org/10.1097/00000542-197805000-00007

[4] Turner DA, Smith G. Evaluation of the combined effects of atropine and neostigmine on the lower oesophageal sphincter. $\mathrm{Br} \mathrm{J}$ Anaesth. 1985; 57: 956-9. PMid: 4041322. https://doi.org/10.1093/ $\mathrm{bja} / 57.10 .956$

[5] Chhibber AK, Lustik SJ, Thakur R, et al. Effects of anticholinergics on postoperative vomiting, recovery, and hospital stay in children undergoing tonsillectomy with or without adenoidectomy. Anesthesiology. 1999; 90: 697-700. PMid: 10078669. https: //doi.org/10.1097/00000542-199903000-00010

[6] Sasaki N, Meyer MJ, Malviya SA, et al. Effects of neostigmine reversal of nondepolarizing neuromuscular blocking agents on postoperative respiratory outcomes: a prospective study. Anesthesiology. 2014; 959-968. PMid: 25225821. https://doi.org/10.1097/ ALN. 0000000000000440

[7] Murphy GS, Szokol JW, Marymont JH, et al. Residual neuromuscular blockade and critical respiratory events in the postanesthesia care unit. Anesth Analg. 2008; 107: 130-7. PMid: 18635478. https://doi.org/10.1213/ane.0b013e31816d1268

[8] Herbstreit F, Peters J, Eikermann M. Impaired upper airway integrity by residual neuromuscular blockade: Increased airway collapsibility and blunted genioglossus muscle activity in response to negative pharyngeal pressure. Anesthesiology. 2009; 110: 125360. PMid: 19417617. https://doi.org/10.1097/ALN.0b013e 31819 faa71

[9] Murphy GS, Szokol JW, Marymont JH, et al. Intraoperative acceleromyographic monitoring reduces the risk of residual neuromuscular blockade and adverse respiratory events in the postanesthesia care unit. Anesthesiology. 2008; 109: 389-98. PMid: 18719436. https://doi.org/10.1097/ALN.0b013e318182af3b

[10] Butterly A, Bittner EA, George E, et al. Postoperative residual curarization from intermediate-acting neuromuscular blocking agents delays recovery room discharge. Br J Anaesth. 2010; 105: 304-9. PMid: 20576632. https ://doi.org/10.1093/bja/aeq157

[11] Yu B, Ouyang B, Ge S, et al. Incidence of postoperative residual neuromuscular blockade after general anesthesia: a prospective, multicenter, anesthetist-blind, observational study. Curr Med Res Opin. 2016; 32(1): 1-9. PMid: 26452561. https ://doi.org/10.1185/ 03007995.2015 .1103213

[12] Cheng CR, Sessler DI, Apfel CC. Does neostigmine administration produce a clinically important increase in postoperative nausea and vomiting? Anesth Analg. 2005; 101(5): 1349-55. PMid: 16243993. https://doi.org/10.1213/01.ANE.0000180992.76743.C9

[13] Koyuncu O, Turhanoglu S, Ozbakis Akkurt C, et al. Comparison of sugammadex and conventional reversal on postoperative nausea and vomiting: a randomized, blinded trial. J Clin Anesth. 2015(1): 51-6. PMid: 25544263. https://doi.org/10.1016/j.jclina ne.2014.08.010

[14] Ledowski T, Falke L, Johnston F, et al. Retrospective investigation of postoperative outcome after reversal of residual neuromuscular blockade: sugammadex, neostigmine or no reversal. Eur J Anaesthesiol. 2014; 31(8): 423-9. PMid: 24296853. https://doi.org/10 $.1097 / \mathrm{EJA} .0000000000000010$

[15] Hogg RM, Mirakhur RK. Sugammadex: a selective relaxant binding agent for reversal of neuromuscular block. Expert Rev Neurother 2009; 9(5): 599-608. PMid: 19402771. https://doi.org/10.1 586/ern.09.22 
[16] Abad-Gurumeta AA, Ripolles-Melchor J, Casans-Frances R, et al. A systematic review of sugammadex vs neostigmine for reversal of neuromuscular blockade. Anaesthesia. 2015; 70: 1441-1452. PMid: 26558858. https://doi.org/10.1111/anae.13277

[17] Carron M, Zarantonello F, Lazzarotto N, et al. Role of sugammadex in accelerating postoperative discharge: A meta-analysis. J Clin Anesth. 2017; 39: 38-44. PMid: 28494905. https ://doi.org/10.1016/ j.jclinane.2017.03.004

[18] Caldwell JE, Miller RD. Clinical implications of sugammadex. Anaesthesia. 2009; 64(Suppl 1): 66-72. PMid: 19222433. https: //doi.org/10.1111/j.1365-2044.2008.05872.x

[19] Putz L, Dransart C, Jamart J, et al. Operating room discharge after deep neuromuscular block reversed with sugammadex compared with shallow block reversed with neostigmine: a randomized controlled trial. J Clin Anesth. 2016; 35: 107-113. PMid: 27871505. https://doi.org/10.1016/j.jclinane.2016.07.030

[20] Hristovska AM, Duch P, Allingstrup M, et al. Efficacy and safety of sugammadex versus neostigmine in reversing neuromuscular blockade in adults. Cochrane Database Syst Rev. 2017; 8: CD012763. PMid: 28806470. https://doi.org/10.1002/14651858.CD0 12763

[21] Carron M, Zarantonello F, Tellaroli P, et al. Efficacy and safety of sugammadex compared to neostigmine for reversal of neuromuscular blockade: a meta-analysis of randomized controlled tri- als. J Clin Anesth. 2016; 35: 1-12. PMid: 27871504. https: //doi.org/10.1016/j.jclinane.2016.06.018

[22] Porta CR, Foster A, Causey MW, et al. Operating room efficiency improvement after implementation of a postoperative team assessment. J Surg Res. 2013; 180(1): 15-20. PMid: 23298950. https : //doi.org/10.1016/j.jss.2012.12.004

[23] Fong AJ, Smith M, Langerman A. Efficiency improvement in the operating room. J Surg Res. 2016; 204(2): 371-383. PMid: 27565073 https://doi.org/10.1016/j.jss.2016.04.054

[24] Childers CP, Maggard-Gibbons M. Understanding Costs of Care in the Operating Room. JAMA Surg. 2018; 153(4): e176233. PMid: 29490366. https ://doi.org/10.1001/jamasurg. 2017.6233

[25] Macario A. What does one minute of operating room time cost? J Clin Anesth. 2010; 22: 233-236. PMid: 20522350. https: //doi.org/10.1016/j.jclinane.2010.02.003

[26] Carron M, Baratto F, Zarantonello F, et al. Sugammadex for reversal of neuromuscular blockade: a retrospective analysis of clinical outcomes and cost-effectiveness in a single center. Clinicoecon Outcomes Res. 2016; 8: 43-52. PMid: 26937203. https ://doi.org/ 10. $2147 /$ CEOR.S100921

[27] Paton F, Paulden M, Chambers D, et al. Sugammadex compared with neostigmine/glycopyrrolate for routine reversal of neuromuscular block: a systematic review and economic evaluation. Br J Anaesth. 2010; 105: 558-567. PMid: 20935005. https ://doi .org/10.109 $3 / \mathrm{bja} / \mathrm{aeq} 269$ 